\title{
Is There a Need for Neonatal Screening of Glucose-6-Phosphate Dehydrogenase Deficiency in Canada?
}

\author{
Aaron Leong*
}

\section{INTRODUCTION AND EPIDEMIOLOGY OF G6PD DEFICIENCY}

Glucose-6-phosphate dehydrogenase (G6PD) deficiency, a hereditary predisposition to hemolysis, is an X-linked disorder of antioxidant homeostasis that is caused by mutations in the G6PD gene. An estimated four hundred million people worldwide are affected. Hence, G6PD deficiency is the most common enzymopathy in the world (3). In areas where malaria is endemic, G6PD deficiency has a prevalence of $5 \%$ to $25 \%$. Non-endemic areas have less than $5 \%$ of their population afflicted with the disease. Several epidemiology studies have identified pockets in Asia and the Middle East with prevalence of the disease as high as 62\% (Kurdish Jews) (1) and 31\% (Northern Vietnam) (2). Within certain population subgroups of the North America, especially blacks, and also among descendents of immigrants from East Asia, Southeast Asia, Greece, Italy and Sephardic Jews, the incidence of G6PD deficiency may be sufficiently high to merit concern (4).

In light of the high prevalence of this disease in many populations around the world, newborn screening for G6PD deficiency has been implemented and incorporated into the screening program in several non-western countries, such as in the Middle East, Eastern Europe and Southeast Asia (5). An analysis of the cost-effectiveness of G6PD deficiency population screening in Canada is necessary, considering the significant influx of immigrants from at-risk populations in Canada over the last 50 years. On average, around a hundred and fifty thousand new migrants uproot themselves from regions around he globe to establish themselves in Canada each year. This massive change in demographics has been exceptionally pronounced in the past decade. Immigration numbers have surged to over two hundred thousand per year; the majority $(\sim 70 \%)$ of these new Canadians come from Asia, the pacific, Africa and the Middle East (6).

\footnotetext{
* To whom correspondence should be addressed: Aaron Leong

Si Arn BSc (Physiology) 2002, MDCM 2007, McGill University, 1537 Summerhill Ave, Apt \#208, Montreal Quebec H3H 1C2 E-mail: aaron.leong@mail.mcgill.ca
}

\section{BIOCHEMISTRY AND NATURAL HISTORY OF G6PD DEFICIENCY}

G6PD is an enzyme in the pentose phosphate pathway, a metabolic pathway that supplies reducing energy to cells, in particular erythrocytes, by maintaining the level of nicotinamide adenine dinucleotide phosphate (NADPH). NADPH in turn maintains the level of glutathione that helps protect erythrocytes against oxidative damage. In states of oxidative stress, glutathione is rapidly consumed and the build up of oxidants can cause the red cell to lyse. Hence, G6PD deficiency most commonly manifests as either prolonged neonatal jaundice or acute hemolytic anemia. Patients of G6PD deficiency are almost exclusively male, due to the X-linked pattern of inheritance, but female carriers can be clinically affected due to lyonization. Lyonization is the random inactivation of an X-chromosome in certain cells, which creates a population of G6PD deficient erythrocytes coexisting with normal cells.

The peak incidence of neonatal jaundice occurs during the second or third day of life. The severity of the jaundice ranges from subclinical to levels compatible with kernicterus, a condition in infants characterized by damage to brain centers due to high levels of bilirubin. Acute hemolytic anemia usually begins within hours of an oxidative stress and ends when G6PD deficient erythrocytes have hemolyzed; therefore, the severity of the anemia associated with these acute hemolytic episodes is proportionate to the deficiency of G6PD and oxidative stress. Viral and bacterial infections are the most common triggers, but many drugs and toxins can also precipitate hemolysis (3). The disorder, favism, in a G6PD deficient patient results from hemolysis secondary to the ingestion of fava beans, which contain beta-glycosides and naturally occurring oxidants. One such peroxidative component of fava beans is divicine, which reduces catalase activity in G6PD-deficient erythrocytes (14). Interestingly, G6PD deficiency also increases the risk for certain unrelated diseases. For example, it has been shown that there is an increased clinical incidence of G6PD deficiency in female patients with multi-lineage clonal marrow disorders (15).

Likewise, G6PD deficiency has been implicated in the pathogenesis of a number of common diseases. It has 
been found that increased oxidative stress and a decrease in the generation of nitric oxide (NO), which are the pathologic characteristics found in G6P deficiency, have been connected to the development of hypertension, diabetes mellitus and atherosclerosis. NADPH, which is generated by G6PD, is a co-factor in the synthesis of nitric oxide. Hence, G6PD deficiency could result in lower NO production. In addition, G6PD deficiency could lead to hyperglycemia, making more glucose available for the non-enzymatic production of advanced glycosylation end products. It has been suggested that these end-products ultimately increase superoxide anions and quench nitric oxide (16). Cardiac dysfunction might also be aggravated by a deficiency in G6PD. As G6PD is a critical antioxidant enzyme, essential for maintenance of cytosolic redox status in cardiomyocytes, deficiencies may contribute to cardiac dysfunction through increased susceptibility to free radical injury and impairment of intracellular calcium transport (17).

G6PD deficiency might also exaggerate morbidity in some infections and increase the risk of Toxoplasmosis infection by 2.5 fold. G6PD deficiency affects our immune response to infection in two contrasting ways. The first mechanism that has been suggested is an exaggeration of the inflammatory response. It has been observed that severely injured G6PD deficient patients tend to have an augmented inflammatory response compared to non-deficient trauma patients. A reduction in the capacity to produce IL-10, a signaling molecule involved in immunosuppression and regulation of $\mathrm{T}$ helper cell responses, may be an intrinsic characteristic of G6PD-deficient monocytes; this attenuated production might be a contributing mechanism to the difference in the level of inflammation observed (18). The second mechanism is a decrease in the normal phagocytic response (19). Indeed, the production of $\mathrm{H}_{2} \mathrm{O}_{2}$ and superoxide has been found to be also significantly impaired in G6PDdeficient granulocytes (20).

\section{G6PD-D-HEMOLYSIS-INDUCING DRUGS}

As previously established, understanding of the adverse effects of drugs in G6PD deficiency is quintessential for the post-natal counseling of this enzymopathy. A number of drugs have been reported to have a potential hemolytic effect on G6PD-deficient individuals. These include primaquine, chloramphenicol and sulfanilamide, which in one study, caused significant concentration-dependent reductions of glutathione levels in G6PD-deficient red cells when compared to normal red cells (21). Several other drugs have been found to be associated with G6PD deficiency-related hemolytic events but the precise causative link has not been fully investigated. Some examples in case reports are glyburide (22), methylene blue $(23,24)$, nitrofurantoin and aspirin. G6PD deficient individuals might also be at greater risk of being exposed to hemolytic inducing environmental or household chemicals in addition to the prescribed drugs mentioned above. Such triggers include naphthalene (25) and henna $(26,27,28)$.

\section{MANAGEMENT OF G6PD DEFICIENCY}

G6PD deficiency should be suspected in patients of African, Mediterranean, or Asian ancestry who present with either an acute hemolytic episode or neonatal jaundice. Unfortunately, according to Kaplan and Hammerman (4), many pediatricians and neonatologists practicing in the United States or Canada erroneously regard G6PD deficiency as a condition confined to the Middle East or Orient and with little application to the patients under their care. The importance of eliciting an adequate ethnic background history from both parents cannot be underestimated. Compounding this ignorance, is the false impression amongst many physicians that only G6PD-deficient premature infants are at increased risk for spontaneous hemolysis or neonatal hyperbilirubinemia while full term G6PD-deficient neonates of this population subgroup go unaffected (4).

The key to management of G6PD deficiency is prevention of hemolysis by prompt treatment of infections and avoidance of drug and household triggers, which are discussed in a later section of this paper. Patients presenting with severe anemia and hemolysis may require resuscitation and erythrocyte transfusion, while babies with neonatal jaundice tend to respond well to standard therapies like hydration, light therapy and exchange transfusion (3). Thus, if a neonate is found to be G6PD deficient, counselling for the parents and an establishment of breastfeeding practices might be excellent prophylactic measures in preventing hemolytic crises later in life. Undoubtedly, a good knowledge of chemotherapeutic drugs, household agents and other environmental triggers of hemolytic anemia in G6PD deficiency are vital for all physicians to not only reduce the incidence of iatrogenic-induced hemolytic events but also augment awareness amongst at-risk individuals.

\section{NEONATAL SCREENING FOR G6PD DEFICIENCY}

The most eminent public health efforts in genetics are government-driven programs that carry out neonatal population screening to identify infants with genetic disorders for which early treatment can prevent or at

Table 1. Adapted from reference 29

\begin{tabular}{l} 
CRITERIA FOR NEWBORN SCREENING \\
\hline 1 Treatment has to be available \\
2 Early institution of treatment before symptoms manifests has \\
been shown to reduce the severity of the illness \\
3 Routine observation and physical examination will not reveal the \\
disorder and so a test is required \\
4 A rapid and economical laboratory test is available that is highly \\
sensitive and specific \\
5 The condition is frequent and serious enough to justify the \\
expense of screening (cost-effectiveness) \\
6 The social infrastructure is in place to inform the newborn's \\
parents and physicians of the results of the screening test, confirm \\
the test results, and institute appropriate treatment and counseling
\end{tabular}

least ameliorate the consequences. Genetic screening can identify persons with genotypes associated with disease, carrier states or predisposition to disease by examining all members of a designated population, regardless of family history. To date, this public health activity for G6PD deficiency has not been 
initiated in Canada. In order to determine whether the G6PD deficiency screening should be implemented as the standard procedure in Canada, one should first determine its suitability and cost-effectiveness by consulting the criteria in Table 1 for guidance (29).

\section{DOES NEONATAL SCREENING FOR G6PD DEFICIENCY MEET THE CRITERIA?}

Screening for G6PD deficiency does abide by the above criteria to some extent. Though a cure does not exist for this condition, recognizing that kernicterus is a serious contributor to newborn mortality and morbidity in G6PD deficient babies should be enough of an impetus to start preventive measures. The onset of kernicterus could be curbed by prophylactic avoidance of triggers and rapid instigation of treatment for infections.

Singapore has embraced this concept and established a mass newborn screening program for G6PD deficiency in 1965. G6PD deficient newborns are identified at birth by measuring the G6PD activity in cord blood. They are then physically protected from triggers by keeping them in the hospital for up to the first two weeks of life. Their parents are counseled on the drugs and household triggers of hemolytic crises. With these preventative measures, the incidence of kernicterus has dropped dramatically and in the last 20 years, there has been only one reported case of kernicterus in newborns with G6PD deficiency in Singapore (5).

A later study done in Singapore revealed that $55 \%$ of G6PD-deficient newborns did not require phototherapy at all (30). This implies that without newborn screening to identify asymptomatic G6PD deficient newborns, these infants run a greater risk of unexpected hemolytic anemia if they unknowingly expose themselves to hemolytic triggers later in life. This goes to show that early institution of treatment does reduce or eliminate morbidity of the disease, which satisfies the second criteria for newborn screening. Furthermore, clinically asymptomatic G6PD deficient neonates, who represent a large proportion of all afflicted neonates (30), cannot be picked up by routine physical examinations. This means that a laboratory test is warranted to distinguish normal from diseased and, for this reason, the third criterion for newborn screening is fulfilled.

To meet the fourth criteria for neonatal screening, an economical laboratory test must be available. A rapid and inexpensive test for G6PD activity in erythrocytes, namely, the Beutler fluorescent spot test is in existence. The test works by visually identifying NADPH produced by G6PD under ultraviolet light.

Situated in a region endemic to malaria, the fifth criteria for newborn screening of G6PD deficiency was easily met in Singapore. Singapore has identified three clinical syndromes associated with G6PD deficiency, namely, severe hemolysis in neonates with kernicterus, and hemoglobinuria. Among the Chinese in Singapore, three common molecular variants, Canton, Kaiping and Mediterranean, have been identified to occur in higher frequencies. In Malays, 6 different deficient variants are known to occur with significant frequencies in Singapore (12). A later study on the incidence of this deficiency led to the observation of racial frequency variation, that is, G6PD deficiencies in $3.94 \%$ of Chinese infants, $2.95 \%$ of Malays and $0.66 \%$ of Indians
(3).

Nonetheless, despite G6PD deficiency being one of the most common inherited metabolic disorders, the magnitude of the problem in Canada is unknown and studies in North America have not determined the incidence of severe hyperbilirubinemia in G6PDdeficient neonates in any subgroups with a high potential for G6PD deficiency in North America. A large epidemiological study of G6PD-deficiencyassociated neonatal hyperbilirubinemia in high-risk minority population subgroups would be necessary to elucidate the true dimensions of the problem (4). Consequently, the fifth criterion for newborn screening of G6PD deficiency in Canada or the United States is not met until sufficient research is carried out in this part of the world.

\section{CONCLUSION}

Rapid changes in the ethnic make-up of the Canadian population in recent times have resulted in more diversity in Canada. This expanding diversity on one hand enriches the cultural and social front but, on the other hand, puts additional demands on the healthcare system. Physicians need to be constantly vigilant in assessing genetic diseases and the ethnic-specific health problems of their patients.

Moreover, it is also reasonable to infer that G6PD deficiency is on the rise in Canada. Along side, an increase incidence of the disease complications, such as kernicterus and hemolytic anemia, would probably ensue. Therefore, making adjustments to Canada's health management plans, to effectively treat this genetic disorder, is essential. These changes could include the implementation of newborn screening of atrisk population to identify deficient individuals, extensions of hospital stays for afflicted newborns, the rapid treatment of infections, and the initiation of counseling for G6PD-deficiency families. Counseling G6PD families should be aimed at increasing awareness of hemolytic triggers. In addition, the above measures have to be executed in conjunction with a better understanding of chemical exposure-related hemolytic events in G6PD deficiency. For this reason, it is important to initiate and accelerate research aimed at uncovering other agents which could cause hemolysis in patients with metabolic and blood pathologies.

In order to satisfy the criteria for newborn screening, investigations must to be devoted to measuring the frequencies of G6PD mutations in the Canadian populations and collecting data on the incidence of kernicterus and hemolytic anemia in G6PD deficient individuals. Thereafter, a more accurate cost-benefit analysis of a neonatal screening program for G6PD deficiency can be performed.

\section{REFERENCES}

1. Steensma DP, Hoyer JD, Fairbanks VF. Hereditary Red Blood Cell Disorders in Middle Eastern Patients. Tutorial: Mayo Clinic Proceedings. 2001 Mar; 76(3):285-93.

2. Verle P, Nhan DH, Tinh TT, Uyen TT, Thuong ND, Kongs A, Stuyft P, Coosemans M. Glucose-6-phosphate Dehydrogenase Deficiency in Northern Vietnam. Tropical Medicine \& International Health. 2000 Mar; 5(3):203-6.

3. Boerkoel S, Yip YY: Mass Newborn Screening for Glucose-6Phosphate Dehydrogenase Deficiency in Singapore. Southeast Asian Journal of Tropical Medicine \& Public Health. 30 Suppl 
1999; 2:70-1.

4. Kaplan M, Hammerman C. Glucose-6-phosphate Dehydrogenase -deficient Neonates. A Potential Cause for Concern in North America. Pedriatrics. 2000 Dec; 16(6):14789.

5. Joseph R, Ho LY, Gomez JM, Rajdurai VS, Sivasankaran S, Yip YY. Mass Newborn Screening for Glucose-6-phosphate Dehydrogenase Deficiency in Singapore. Southeast Asian Journal of Tropical Medicine \& Public Health. 30 Suppl 1999; 2:70-1.

6. Facts and Figures 2002: Immigration Overview. In http://www.cic.gc.ca/english/pub/facts2002/index.html. Accessed on 20 November 2004

7. Migot-Nabias F, Mombo LE, Luty AJ, Dubois B, Nabias R, Bisseye C, Millet P, Lu CY, Deloron P. Human Genetic Factors Related to Susceptibility to Mild Malaria in Gabon. Genes \& Immunity. 2000 Oct; 7:435-41.

8. Ahmed SG, Ibrahim UA: Clinical Significance of Glucose-6Phosphate Dehydrogenase Deficiency in Nigerian Patients with Sickle Cell Disease. Nigerian Postgraduate Medical Journal. 2002 Dec; 9(4):181-5.

9. Aster JC. Red Blood Cell and Bleeding Disorders. In Kumar V, Abul K, Fausto N. Robbins and Contran Pathologic Basis of Disease, 7th ed, Philadelphia: Elsevier Saunders; 2005: 619659.

10. Lang KS, Roll B, Myssina S, Schittenhelm M, Scheel-Walter HG, Kanz L, Fritz J, Lang F, Huber SM, Wieder T. Enhanced Erythrocyte Apoptosis in Sickle Cell Anemia, Thalassemia and Glucose-6-phosphate Dehydrogenase Deficiency. Cellular Physiology \& Biochemistry 2002; 12(5-6):365-72.

11. Mehta A, Mason PJ, Vulliamy TJ. Glucose-6-phosphate Dehydrogenase Deficiency. Balliers Best Prac Res Clin Hematol 2000; 13:2.

12. Quak SH, Saha N, Tay JS. Glucose-6-phosphate Dehydrogenase Deficiency in Singapore. Annals of the Academy of Medicine, Singapore. 1996 Jan; 25(1):45-8.

13. Huang CS, Hung KL, Huang MJ, Li YC, Liu TH, Tang TK. Neonatal Jaundice and Molecular Mutations in Glucose-6phosphate Dehydrogenase Deficient Newborn Infants. American Journal of Hematology 1996 Jan; 51(1):19-25.

14. Gaetani GF, Rolfo M, Arena S, Mangerini R, Meloni GF, Ferraris AM. Active Involvement of Catalase during Hemolytic Crises of Favism. Blood Aug 1 1996; 88(3):1084-8.

15. Au WY, Ma SK, Lie AK, Liang R, Cheng T, Kwong YL. Glucose-6-phosphate Dehydrogenase Deficiency and Hematopoietic Stem Cell Transplantation. Bone Marrow Transplantation 2002 Mar; 29(5):399-402.

16. Gaskin RS, Estwick D, Peddi R. G6PD Deficiency: Its Role in the High Prevalence of Hypertension and Diabetes Mellitus. Ethnicity \& Disease 2001 Fall; 11(4):749-54.

17. Jain M, Brenner DA, Cui L, Lim CC, Wang B, Pimentel DR, Koh S, Sawyer DB, Leopold JA, Handy DE, Loscalzo J, Apstein CS, Liao R. Glucose-6-phosphate Dehydrogenase Modulates Cytosolic Redox Status and Contractile Phenotype in Adult Cardiomyocytes. Circulation Research 2003 Jul 25; 93(2):9-16.

18. Liese AM, Siddiqi MQ, Siegel JH, Deitch EA, Spolarics Z. Attenuated Monocyte IL-10 Production in Glucose-6-phosphate Dehydrogenase-deficient Trauma Patients. Shock 2002 Jul; 18(1):18-23.

19. Tabbara KF, Sharara NA, Al-Momen AK. Toxoplasmosis in a Group of Glucose-6-phosphate Dehydrogenase Deficient patients. Saudi Medical Journal 2001 Apr; 22(4):330-2.

20. Tsai KJ, Hung IJ, Chow CK, Stern A, Chao SS, Chiu DT. Impaired Production of Nitric Oxide, Superoxide, and Hydrogen Peroxide in Glucose 6-phosphate-dehydrogenase-deficient
Granulocytes. FEBS Letters 1998 Oct 9; 436(3):411-4.

21. Ali NA, al-Naama LM, Khalid LO. Haemolytic Potential of Three Chemotherapeutic Agents and Aspirin in Glucose-6phosphate Dehydrogenase Deficiency. Eastern Mediterranean Health Journal 1999 May; 5(3):457-64.

22. Meloni G, Meloni T: Glyburide-induced Acute Hemolysis in a G6PD-deficient Patient with NIDDM. British Journal of Haematology 1996 Jan; 92(1):159-60.

23. Liao YP, Hung DZ, Yang DY. Hemolytic Anemia after Methylene Blue Therapy for Aniline-induced Methemoglobinemia. Veterinary \& Human Toxicology 2002 Feb; 44(1):19-21.

24. Gauthier TW: Methylene Blue-induced Hyperbilirubinemia in Neonatal Glucose-6-phosphate Dehydrogenase (G6PD) Deficiency. Journal of Maternal-Fetal Medicine 2000 Jul-Aug; 9(4):252-4.

25. Santucci K, Shah B. Association of Naphthalene with Acute Hemolytic Anemia. Academic Emergency Medicine 2000 Jan; 7(1):42-7.

26. Kok AN, Ertekin MV, Ertekin V, Avci B. Henna (Lawsonia inermis Linn.) Induced Hemolytic Anemia in Siblings. International Journal of Clinical Practice 2004 May; 58(5):5302 .

27. Kandil HH, al-Ghanem MM, Sarwat MA, al-Thallab FS. Henna (Lawsonia inermis Linn.) Inducing Hemolysis among G6PD-deficient Newborns. A New Clinical Observation. Annals of Tropical Paediatrics 1996 Dec; 16(4):287-91.

28. Zinkham WH, Oski FA: Henna: a Potential Cause of Oxidative Hemolysis and Neonatal Hyperbilirubinemia. Pediatrics. 1996 May; 97(5):707-9.

29. Nussbaum RL, McInnes RR, Willard HF Thompson and Thompson Genetics in Medicine, 6th ed, Philadelphia: WB Saunders Company;391-398

30. Lim HH, Daniel LM, Lee J, Tan MC. Predicting Significant Hyperbilirubinaemia and Early Discharge for Glucose-6phosphate Dehydrogenase Deficient Newborns. Annals of the Academy of Medicine, Singapore 2003 Mar; 32(2):257-61.

Aaron Leong (M.D. C.M. 2007) is a fourth-year medical student at McGill University. He received his B.Sc. in Physiology from the National University of Singapore in 2002. He hopes to train in internal medicine or pediatrics and specialize in critical care. His interests include both qualitative and quantitative research in sociobiology, epidemiology, public health and medical education. He has published in Medical informatics and the Internet in medicine on multi-channel video methods used to assess the effectiveness of clinical consultations. 